\title{
Collaborative work on evaluation of ovarian toxicity 15) Two- or four-week repeated-dose studies and fertility study of bromocriptine in female rats
}

\author{
Toshihiko Kumazawa, Atsushi Nakajima, Tsukasa Ishiguro, Zhu Jiuxin, Takashi Tanaharu, \\ Hiromi Nishitani, Yukiko Inoue, Satoko Harada, Ikuo Hayasaka and Yoshiaki Tagawa
}

Pharmaceutical Research Laboratories, Sanwa Kagaku Kenkyusho Co., Ltd., 363 Shiosaki, Hokusei-cho, Inabe-shi, Mie 511-0406, Japan

(Received December 10, 2008)

\begin{abstract}
The main focus of this study is to determine the optimal administration period concerning toxic effects on ovarian morphological changes in a repeated-dose toxicity study. To assess morphological and functional changes induced in the ovary by bromocriptine, the compound was administered to female rats at dose levels of $0,0.08,0.4$ and $2 \mathrm{mg} / \mathrm{kg}$ for the 2 - or 4-week repeated-dose toxicity study, and for the female fertility study from 2 weeks prior to mating to day 7 of gestation. In the 2week repeated-dose toxicity study, increase of ovarian weights was observed at $2 \mathrm{mg} / \mathrm{kg}$. In the 4 -week repeated-dose toxicity study, ovarian weights were increased at 0.4 and $2 \mathrm{mg} / \mathrm{kg}$. The number of corpora luteum was increased in the 0.4 and $2 \mathrm{mg} / \mathrm{kg}$ groups of the 2 - and 4-week repeated-dose toxicity studies by histopathological examination of the ovaries. Bromocriptine did not affect estrous cyclicity in 2- and 4-week repeated dosing. In the female fertility study, although animals in any groups mated successfully, no females in 0.4 and $2 \mathrm{mg} / \mathrm{kg}$ groups were pregnant. There were no adverse effects on reproductive performance in the $0.08 \mathrm{mg} / \mathrm{kg}$ group. Based on these findings, the histopathological changes in the ovary are considered important parameters for evaluation of drugs including ovarian damage. We conclude that a 2week administration period is sufficient to detect ovarian toxicity of bromocriptine in a repeated-dose toxicity study.
\end{abstract}

Key words: Ovarian toxicity, Repeated-dose toxicity study, Female fertility study, Bromocriptine mesylate, Rats

\section{INTRODUCTION}

As part of a collaborative study on toxicity related to female fertility, we performed experiments using bromocriptine, a dopamine agonist which inhibits prolactin secretion.

Bromocriptine has been in clinical use primarily for treatment of hyperprolactinemia and Parkinson's disease. The prolactin-suppressant properties of the drug in rats have been well-documented (Flückiger et al., 1982). In particular, attention has focused on abortifacient effects of bromocriptine administration to pregnant rats during preand early post-implantation stages of embryonic development (Flückiger and Wagner, 1968). The physiological basis of this action entails withdrawal of prolactin stimulus for progesterone production by the corpus luteum. Prolactin, with luteinizing hormone, is an essential luteo- trophin during early rat pregnancy (Rothchild, 1981), and a decrease in circulating concentration of prolactin, due to pituitary dopamine receptor activation by bromocriptine, results in a fall in serum progesteron concentration to a level below that needed to maintain pregnancy. Bromocriptine-induced hypoprolactinemia reportedly alters corpus luteum formation and ovary function in female rats (Kauppila et al., 1988). Thus, a bromocriptine-induced blockade of prolactin surges and subsequent reduction in progesterone secretion during very early pregnancy in the rat serve to prevent implantation (Kofler et al., 1981; Müller et al., 1980).

The present study was designed to determine whether 2- or 4-week repeated-dose toxicity study can be used as an alternative or not to detecting potential ovarian toxicity instead of female reproductive function tests in a fertility study.

Correspondence: Toshihiko Kumazawa (E-mail: t_kumazawa@mb4.skk-net.com) 


\section{MATERIALS AND METHODS}

\section{Test article}

Bromocriptine (bromocriptine mesylate, BIOMOL International LP, Exeter, UK) was used for this study. Bromocriptine was suspended in $30 \%$ ethanol diluted with saline at a volume of $0.1 \mathrm{ml} / 100 \mathrm{~g}$ body weight. Control animals were given the same volume of the vehicle solution.

\section{Animals}

$\mathrm{Crl}: \mathrm{CD}(\mathrm{SD})$ female rats were purchased from Charles River Japan, Inc. (Tokyo, Japan). Animals were 6-weeksold for the repeated-dose toxicity studies, and 10-weeksold for female fertility study at the onset of dosing. Agematched male rats were also prepared for the female fertility study. They were maintained in an air-conditioned barrier-system animal room with an ambient temperature of $22 \pm 3^{\circ} \mathrm{C}$, relative humidity of $55 \pm 5 \%$ and a $12-\mathrm{hr}$ light/dark cycle. All animals were allowed free access to commercial rodent chow, CRF-1 (Oriental Yeast Co., Ltd., Tokyo, Japan) and tap water. Japanese laws concerning the protection and control of animals, standards related to care and management of experimental animals and the Guide of Animal Experimentation of Sanwa Kagaku Kenkyusho were strictly followed throughout the study.

\section{Study design}

Fig. 1 shows the study design.

\section{Repeated-dose toxicity study}

Forty rats were divided into four groups: the control group consisted of 10 rats that received vehicle only (30\% ethanol solution in saline) subcutaneously once-daily and the three treatment groups consisted of 10 animals respectively administered bromocriptine at concentration of $0.08,0.4,2 \mathrm{mg} / \mathrm{kg}$ subcutaneously once-daily during 2 or 4 weeks. During the study period, daily vaginal smears were taken on the morning to monitor the ovarian cycle pattern. Estrous cycle was classified as proestrus, estrus, metestrus and diestrus. The daily taking of smears continued up to and included the day of autopsy. Body weights and food consumption were measured on days $1,4,8,11$ and 14 after dosing in the 2 -week repeated-dose toxicity study, and on days 1, 4, 8, 11, 14, 18, 22, 25 and 28 after dosing in the 4 -week repeated-dose toxicity study. All rats were sacrificed by exanguination from the abdominal aorta under ether anesthesia and autopsied one day after the end of the administration period. Each animal was weighed before sacrifice, and organs (pituitary, ovary and uterus) were removed and their absolute and relative weights were determined. These organs were fixed in

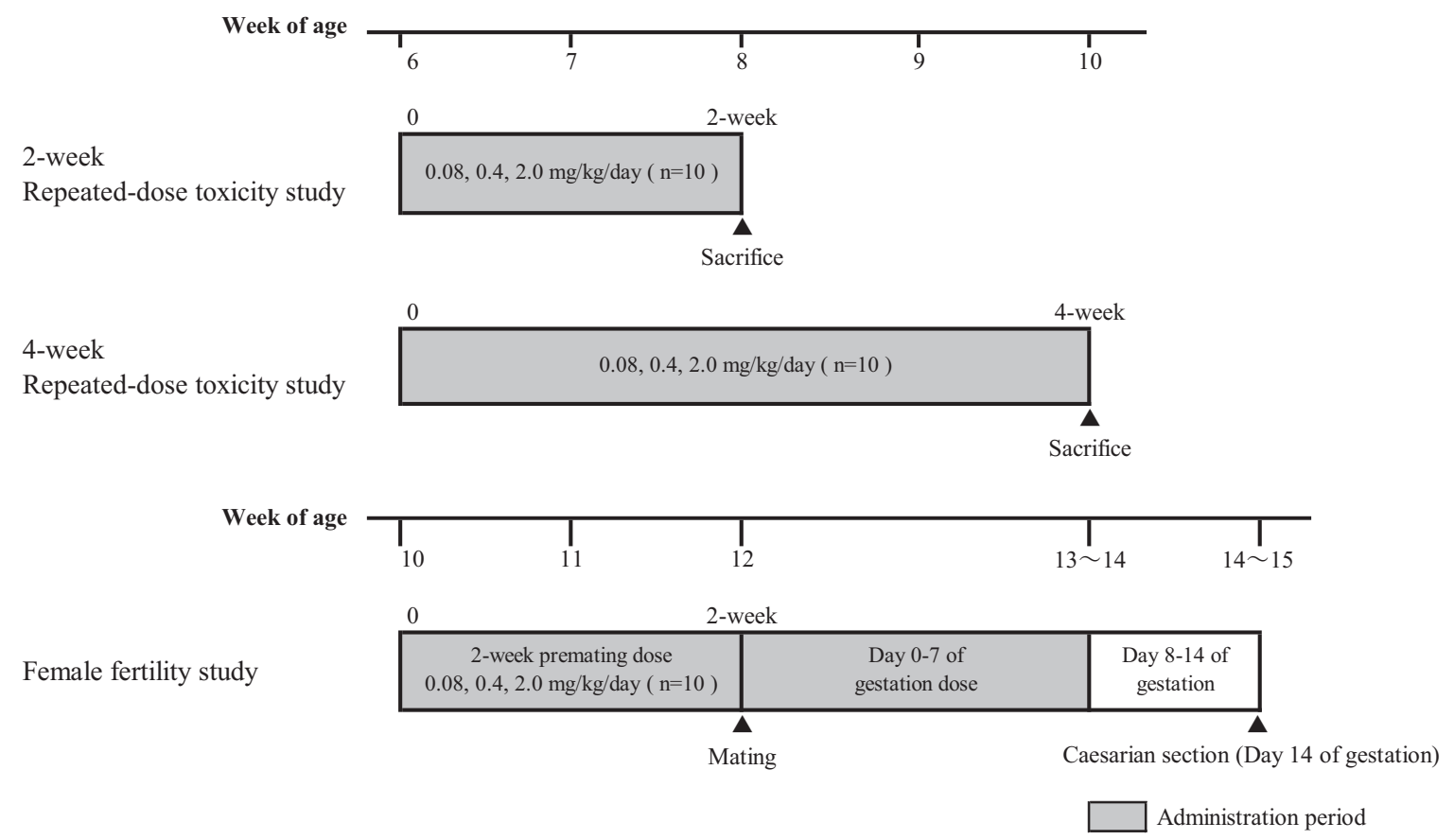

Fig. 1. Experimental design for 2- and 4-week repeated-dose toxicity studies and female fertility study. 
$10 \%$ buffered formalin. After fixation, the bilateral ovaries were transversally halved to observe the maximum area of the ovary, and were dehydrated through a graded alcohol series and embedded in paraffin. The transverse sections were cut at $4 \mu \mathrm{m}$ in thickness and mounted onto slides. For each animal, serial sections were stained with hematoxylin eosin (HE) and proliferating cell nuclear antigen (PCNA) immunohistochemical staining. The prepared histopathological specimens were examined under a light microscope. The number of previously and currently formed corpora lutea were counted. Currently formed corpora lutea appeared at estrus and showed intensive reaction by PCNA staining, while the corpora lutea of the previously estrous cycle appeared in week reaction.

\section{Female fertility study}

Forty rats were divided into four groups: the control group consisted of 10 rats that received vehicle only subcutaneously once-daily and the three treatment groups consisted of 10 animals respectively administered bromocriptine at concentrations of $0.08,0.4,2 \mathrm{mg} / \mathrm{kg}$ subcutaneously once-daily during 14 days prior to mating through day 7 of gestation. Daily vaginal smears were taken on the morning to monitor the ovarian cycle pattern for the pre-mating administration period. Estrous cycle was classified as proestrus, estrus, metestrus and diestrus. The females were mated overnight for a maximum of 2 weeks on a one-to-one basis with untreated males. Copulation was confirmed by the presence of a sperm in the vaginal smear on the following morning, and the day of confirmed copulation was designated as day 0 of gestation. Copulation index and fertility index were calculated. Body weights and food consumption were measured on days $1,4,8,11$ and 14 after dosing, and days $0,3,7$, 9, 11 and 14 of gestation. On day 14 of gestation, females were sacrificed by exsanguination from the abdominal aorta under ether anesthesia and examined for gross pathologic changes. The uterus was opened, and the types of implantation (live and dead fetuses and resorptions) were recorded. Corpora lutea for each ovary were counted. The uterus of each apparently non-pregnant rat was stained with $2 \%$ potassium hydroxide for confirmation of pregnancy status (Yamada et al., 1988).

\section{Statistical analyses}

Statistical comparison was made between any treated group and control groups with SAS software (Ver. 6.12. SAS Institute, Tokyo, Japan). In all cases, a two-tailed test was used and levels of $p<0.01$ and $p<0.05$ were considered significant. Differences between body weight, food consumption, estrous cycle and organ weight (absolute and relative to body weight) in the control and bromocriptine-treated groups were analyzed. Homogeneity of variances was tested by Bartlett's test. When a set of variances was homogenous, comparison with the control was made by Dunnett's multiple comparison test. When a set of variances was not homogenous, comparison with the control group was made by Steel's multiple comparison test. For the number of corpora lutea, implantation, live and dead embryo in the female fertility study, differences between bromocriptine $0.08 \mathrm{mg} / \mathrm{kg}$ group and the control group were examined by $\mathrm{F}$ test for equal variance. If the groups were accepted to be of equal variance, Student's $t$ test was used for comparison of the data. If the data were shown to be of unequal variance by F test, Aspin-Welch's $t$-test was conducted. Wilcoxon's rank sum test was used for pre- and post-implantation loss index.

\section{RESULTS}

\section{Repeated-dose toxicity study}

Throughout the study period, no death was found in any groups of the 2- and 4-week studies. No significant differences between bromocriptine-treated groups and the control group were noted in body weight, food consumption and estrous cycle (Tables 1 and 2) in both the 2- and 4-week studies.

Regarding organ weight, significant increased values in absolute and relative ovary weights were found at $2 \mathrm{mg} /$ $\mathrm{kg}$ in the 2-week study (Table 3), and at 0.4 and $2 \mathrm{mg} / \mathrm{kg}$ in the 4-week study (Table 4), respectively. In the 4-week study, significant decreased values in absolute and/or relative pituitary weights were observed (Table 4).

On histopathological examination, normal primordial follicles, preantral and antral follicles were observed in all groups treated with bromocriptine in the 2- and 4week studies. Bromocriptine 0.4 and $2 \mathrm{mg} / \mathrm{kg}$ groups showed increased numbers of previously formed corpora lutea compared to that of the control group in the 2- and 4-week studies (Tables 5 and 6). No significant change was found in the currently formed corpora lutea in both repeated studies. In the control animals which had normal estrous cyclicity, apoptotic cell death was found in the previously formed corpora lutea, but not in the bromocriptine-treated animals. In the pituitary, the atrophy of intermediate lobe cells was observed in 0.4 and $2 \mathrm{mg} / \mathrm{kg}$ groups of the 2- and 4-week studies (data not shown).

\section{Female fertility study}

There were no deaths or dose-related abnormalities in clinical signs in females at any dose level. Body weights and food consumption were similar to those of controls 
throughout the pre-mating and gestation period. Bromocriptine did not affect estrous cyclicity. The animals in any groups mated successfully. At necropsy of dams, females in the 0.4 and $2 \mathrm{mg} / \mathrm{kg}$ groups were not pregnant. Although uteri of non-pregnant rats were stained with $2 \%$ potassium hydroxide for confirmation of the pregnancy status, there were no implantation sites. Therefore, mating abilities were $100 \%$ in any groups and fertility rates were $100 \%$ in the control and $0.08 \mathrm{mg} / \mathrm{kg}$ groups, and $0 \%$ in the 0.4 and $2 \mathrm{mg} / \mathrm{kg}$ groups, respectively. There were no remarkable changes in the numbers of corpora lutea, implantations and live/dead fetuses in $0.08 \mathrm{mg} / \mathrm{kg}$ group (Table 7).

\section{DISCUSSION}

In the present study, we administered bromocriptine for 2 weeks and compared the effects with those of 4week administration. A further aim of the present study was to examine whether the reproductive toxicity noted in a female fertility study can also be detected in repeateddose toxicity study. Moreover, the non-observed adverse effect level (NOAEL) for the repeated-dose toxicity study focused on the ovary and that for the female fertility study were also compared.

In the repeated-dose toxicity study, an increase ovarian weight was observed at $2 \mathrm{mg} / \mathrm{kg}$ in the 2 -week study, and

Table 1. Clinical observations in 2-week study

\begin{tabular}{lcccc}
\hline Dose (mg/kg/day) & 0 (Control) & 0.08 & 0.4 & 2 \\
\hline No. of Animals (Female) & 10 & 10 & 10 & 10 \\
No. Died or Sacrificed Moribund & 0 & 0 & 0 & 0 \\
$\quad$ Clinical Observations & - & - & - & - \\
$\quad$ Body Weight (g) & $195.6 \pm 10.9$ & $191.6 \pm 10.2$ & $190.5 \pm 9.9$ & $189.8 \pm 11.6$ \\
$\quad$ Day 14 (day of last dosing) & $16.1 \pm 1.9$ & $15.3 \pm 2.2$ & $16.6 \pm 1.5$ & $17.2 \pm 1.7$ \\
$\quad$ Food Consumption (g/day/animal) & $4.1 \pm 0.3$ & $4.0 \pm 0.1$ & $4.0 \pm 0.2$ & $4.0 \pm 0.0$ \\
$\quad$ Day 14 (day of last dosing) & $0 / 10$ & $0 / 10$ & $0 / 10$ & $0 / 10$ \\
$\quad \begin{array}{l}\text { Mean Estrous Cycle (day) } \\
\quad \text { No. Animals } \quad \text { with Irregular Estrous Cycle }{ }^{1)}\end{array}$ & & & \\
\hline
\end{tabular}

Values represent mean \pm S.D.

- : No noteworthy findings

1) Estrous cycle was evaluated as irregular cycle considering frequency of irregular cycle (consecutive estrous or prolongation of estrous cycle) in control animals.

Table 2. Clinical observations in 4-week study

\begin{tabular}{lcccc}
\hline Dose (mg/kg/day) & 0 (Control) & 0.08 & 0.4 & 2 \\
\hline No. of Animals (Female) & 10 & 10 & 10 & 10 \\
$\quad$ No. Died or Sacrificed Moribund & 0 & 0 & 0 & 0 \\
$\quad$ Clinical Observations & - & - & - & - \\
$\quad$ Body Weight (g) & $231.5 \pm 16.0$ & $234.2 \pm 15.9$ & $235.0 \pm 12.1$ & $228.6 \pm 11.1$ \\
$\quad$ Day 28 (day of last dosing) & $16.8 \pm 2.7$ & $17.2 \pm 2.5$ & $18.0 \pm 1.6$ & $17.7 \pm 2.4$ \\
$\quad$ Food Consumption (g/day/animal) & $4.0 \pm 0.1$ & $4.0 \pm 0.1$ & $4.0 \pm 0.3$ & $4.0 \pm 0.1$ \\
$\quad$ Day 28 (day of last dosing) & $0 / 10$ & $0 / 10$ & $0 / 10$ & $0 / 10$ \\
$\quad \begin{array}{l}\text { Mean Estrous Cycle (day) } \\
\quad \text { No. Animals } \quad \text { with Irregular Estrous Cycle }{ }^{1)}\end{array}$ & & & & \\
\hline
\end{tabular}

Values represent mean \pm S.D.

- : No noteworthy findings

1) Estrous cycle was evaluated as irregular cycle considering frequency of irregular cycle (consecutive estrous or prolongation of estrous cycle) in control animals. 
Ovarian toxicity study of bromocriptine in female rats

Table 3. Organ weights in 2-week study

\begin{tabular}{|c|c|c|c|c|c|}
\hline Dose (mg/kg/day) & & 0 (Control) & 0.08 & 0.4 & 2 \\
\hline No. of Animals (Female) & & 10 & 10 & 10 & 10 \\
\hline Body weight at necropsy (g) & & $177.0 \pm 9.5$ & $173.7 \pm 9.0$ & $173.2 \pm 9.3$ & $176.0 \pm 11.1$ \\
\hline \multirow{2}{*}{ Ovary (R) } & $(\mathrm{mg})$ & $45.2 \pm 9.9$ & $49.5 \pm 5.3$ & $52.5 \pm 5.3$ & $56.6 \pm 13.6$ \\
\hline & $(\mathrm{mg} \%)^{1)}$ & $25.6 \pm 5.8$ & $22.8 \pm 2.9$ & $30.3 \pm 2.7$ & $32.2 \pm 7.7$ \\
\hline \multirow{2}{*}{ Ovary (L) } & $(\mathrm{mg})$ & $41.5 \pm 9.8$ & $41.9 \pm 9.1$ & $50.7 \pm 7.9$ & $58.6 \pm 13.0^{* *}$ \\
\hline & $(\mathrm{mg} \%)$ & $23.5 \pm 5.8$ & $24.2 \pm 5.3$ & $29.3 \pm 4.2$ & $33.3 \pm 6.7^{* *}$ \\
\hline \multirow{2}{*}{ Uterus } & (g) & $0.33 \pm 0.10$ & $0.42 \pm 0.23$ & $0.41 \pm 0.19$ & $0.46 \pm 0.23$ \\
\hline & $(\mathrm{g} \%)^{2)}$ & $0.19 \pm 0.05$ & $0.24 \pm 0.13$ & $0.24 \pm 0.11$ & $0.26 \pm 0.13$ \\
\hline \multirow[t]{2}{*}{ Pituitary } & (mg) & $9.4 \pm 1.6$ & $8.6 \pm 1.3$ & $10.3 \pm 1.9$ & $9.9 \pm 3.2$ \\
\hline & $(\mathrm{mg} \%)$ & $5.3 \pm 0.8$ & $5.0 \pm 0.8$ & $5.9 \pm 0.9$ & $5.7 \pm 1.9$ \\
\hline
\end{tabular}

Values represent mean \pm S.D.

$\mathrm{R}$ : right ovary; L: left ovary

**: Significantly different from control $(\mathrm{p}<0.01)$

1) $\mathrm{mg} / 100 \mathrm{~g}$ body weight

2) g/100g body weight.

Table 4. Organ weights in 4-week study

\begin{tabular}{|c|c|c|c|c|c|}
\hline Dose (mg/kg/day) & & 0 (Control) & 0.08 & 0.4 & 2 \\
\hline No. of Animals (Female) & & 10 & 10 & 10 & 10 \\
\hline Body weight at necropsy (g) & & $212.9 \pm 14.8$ & $218.4 \pm 15.9$ & $215.9 \pm 11.6$ & $210.7 \pm 11.5$ \\
\hline \multirow[t]{2}{*}{ Ovary (R) } & (mg) & $50.5 \pm 5.5$ & $53.0 \pm 7.5$ & $75.3 \pm 15.0^{* *}$ & $89.7 \pm 12.9^{* *}$ \\
\hline & $(\mathrm{mg} \%)^{1)}$ & $23.7 \pm 2.5$ & $24.2 \pm 2.3$ & $34.8 \pm 6.2 * *$ & $42.6 \pm 6.3 * *$ \\
\hline \multirow[t]{2}{*}{ Ovary (L) } & (mg) & $49.3 \pm 8.8$ & $50.5 \pm 10.1$ & $73.4 \pm 13.9^{* *}$ & $82.1 \pm 9.2 * *$ \\
\hline & $(\mathrm{mg} \%)$ & $23.3 \pm 4.5$ & $23.0 \pm 3.8$ & $33.8 \pm 5.0^{* *}$ & $39.1 \pm 5.1^{* *}$ \\
\hline \multirow[t]{2}{*}{ Uterus } & (g) & $0.40 \pm 0.16$ & $0.36 \pm 0.10$ & $0.42 \pm 0.22$ & $0.48 \pm 0.28$ \\
\hline & $(\mathrm{g} \%)^{2)}$ & $0.19 \pm 0.07$ & $0.17 \pm 0.05$ & $0.19 \pm 0.10$ & $0.23 \pm 0.13$ \\
\hline \multirow[t]{2}{*}{ Pituitary } & $(\mathrm{mg})$ & $11.9 \pm 2.0$ & $11.0 \pm 1.8$ & $9.7 \pm 1.4^{*}$ & $9.1 \pm 2.3^{* *}$ \\
\hline & $(\mathrm{mg} \%)$ & $5.6 \pm 0.8$ & $5.1 \pm 0.8$ & $4.5 \pm 0.6$ & $4.3 \pm 1.0^{* *}$ \\
\hline
\end{tabular}

Values represent mean \pm S.D.

R: right ovary; L: left ovary

*: Significantly different from control $(\mathrm{p}<0.05) ; * *$ : Significantly different from control $(\mathrm{p}<0.01)$

1) $\mathrm{mg} / 100 \mathrm{~g}$ body weight

2) g/100g body weight

at 0.4 and $2 \mathrm{mg} / \mathrm{kg}$ in the 4-week study. Histopathological findings revealed that the number of previously formed corpora lutea was increased at 0.4 and $2 \mathrm{mg} / \mathrm{kg}$ in the 2 and 4 -week studies. These treatment-related changes were more severe in the 4 -week than in the 2 -week repeated dosing. In addition, the intensity of damages to ovary was observed depending on the dose level. Therefore, the NOAEL for the repeated-dose toxicity study focused on 
Table 5. Pathological changes in 2 -week study

\begin{tabular}{|c|c|c|c|c|c|c|c|c|c|c|c|c|}
\hline Dose (mg/kg) & \multicolumn{3}{|c|}{0 (Control) } & \multicolumn{3}{|c|}{0.08} & \multicolumn{3}{|c|}{0.4} & \multicolumn{3}{|c|}{2} \\
\hline No. of Animals & \multicolumn{3}{|c|}{10} & \multicolumn{3}{|c|}{10} & \multicolumn{3}{|c|}{10} & \multicolumn{3}{|c|}{10} \\
\hline \multicolumn{13}{|l|}{ Ovary } \\
\hline No. examined & $\mathrm{R}: 10$ & $\mathrm{~L}: 10$ & $\mathrm{~W}: 10$ & $\mathrm{R}: 10$ & L:9 1) & $\mathrm{W}: 10$ & $\mathrm{R}: 10$ & L:10 & $\mathrm{W}: 10$ & $\mathrm{R}: 9^{2)}$ & L:10 & $\mathrm{W}: 10$ \\
\hline Decrease in small follicle & 0 & 0 & 0 & 0 & 0 & 0 & 0 & 0 & 0 & 0 & 0 & 0 \\
\hline Decrease in medium follicle & 0 & 0 & 0 & 0 & 0 & 0 & 0 & 0 & 0 & 0 & 0 & 0 \\
\hline Decrease in large follicle & 0 & 0 & 0 & 0 & 0 & 0 & 0 & 0 & 0 & 0 & 0 & 0 \\
\hline Increase in atresia & 0 & 0 & 0 & 0 & 0 & 0 & 0 & 0 & 0 & 0 & 0 & 0 \\
\hline $\begin{array}{l}\text { Increase in corpora lutea } \\
\text { (currently formed) }\end{array}$ & 0 & 0 & 0 & 0 & 0 & 0 & 0 & 0 & 0 & 0 & 0 & 0 \\
\hline $\begin{array}{l}\text { Increase in corpora lutea } \\
\quad \text { (previously formed) }\end{array}$ & 0 & 0 & 0 & 0 & 0 & 0 & 0 & 1 & 1 & 1 & 2 & 2 \\
\hline Slight & 0 & 0 & 0 & 0 & 0 & 0 & 0 & 1 & 1 & 1 & 2 & 2 \\
\hline
\end{tabular}

R: right ovary; L: left ovary; W: whole body;

Slight: the number of corpora lutea was 10 to 14 (2 to 3 fold of control value).

1) One ovary (left) was lost after measurement of organ weight.

2) One ovary (right) was excluded from evaluation, because of including ovarian hilus.

Table 6. Pathological changes in 4-week study

\begin{tabular}{|c|c|c|c|c|c|c|c|c|c|c|c|c|}
\hline Dose $(\mathrm{mg} / \mathrm{kg})$ & \multicolumn{3}{|c|}{0 (Control) } & \multicolumn{3}{|c|}{0.08} & \multicolumn{3}{|c|}{0.4} & \multicolumn{3}{|c|}{2} \\
\hline No. of Animals & \multicolumn{3}{|c|}{10} & \multicolumn{3}{|c|}{10} & \multicolumn{3}{|c|}{10} & \multicolumn{3}{|c|}{10} \\
\hline \multicolumn{13}{|l|}{ Ovary } \\
\hline No. examined & $\mathrm{R}: 10$ & $\mathrm{~L}: 10$ & $\mathrm{~W}: 10$ & $\mathrm{R}: 10$ & $\mathrm{~L}: 10$ & $\mathrm{~W}: 10$ & $\mathrm{R}: 10$ & $\mathrm{~L}: 10$ & $\mathrm{~W}: 10$ & $\mathrm{R}: 10$ & $\mathrm{~L}: 9$ 1) & $\mathrm{W}: 10$ \\
\hline Decrease in small follicle & 0 & 0 & 0 & 0 & 0 & 0 & 0 & 0 & 0 & 0 & 0 & 0 \\
\hline Decrease in medium follicle & 0 & 0 & 0 & 0 & 0 & 0 & 0 & 0 & 0 & 0 & 0 & 0 \\
\hline Decrease in large follicle & 0 & 0 & 0 & 0 & 0 & 0 & 0 & 0 & 0 & 0 & 0 & 0 \\
\hline Increase in atresia & 0 & 0 & 0 & 0 & 0 & 0 & 0 & 0 & 0 & 0 & 0 & 0 \\
\hline $\begin{array}{r}\text { Increase in corpora lutea } \\
\text { (currently formed) }\end{array}$ & 0 & 0 & 0 & 0 & 0 & 0 & 0 & 0 & 0 & 0 & 0 & 0 \\
\hline $\begin{array}{l}\text { Increase in corpora lutea } \\
\text { (previously formed) }\end{array}$ & 0 & 0 & 0 & 0 & 0 & 0 & 4 & 4 & 6 & 8 & 9 & 10 \\
\hline Slight & 0 & 0 & 0 & 0 & 0 & 0 & 4 & 4 & 6 & 6 & 5 & 5 \\
\hline Moderate & 0 & 0 & 0 & 0 & 0 & 0 & 0 & 0 & 0 & 1 & 4 & 4 \\
\hline Marked & 0 & 0 & 0 & 0 & 0 & 0 & 0 & 0 & 0 & 1 & 0 & 1 \\
\hline
\end{tabular}

R: right ovary; L: left ovary; W: whole body;

Slight: the number of corpora lutea was 10 to 14 (2 to 3 -fold of control value).

Moderate: number of corpora lutea was 15 to 19 (3 to 4-fold of control value).

Marked: number of corpora lutea was 20 or more (4 or more-fold of control value).

1) One ovary (left) was excluded from evaluation, because of including ovarian hilus.

the ovary was $0.08 \mathrm{mg} / \mathrm{kg}$ in the 2- and 4-week studies, respectively. The luteolytic action of prolactin in the rat is well known (Rothchild, 1981, 1996). It has been strongly suggested that both prolactin and progesterone are necessary for induction of apoptosis in the regressing corpora lutea (Gaytán et al., 1998; Kiya et al., 1998). Blockade of the prolactin surge with the dopaminergic agonist CB154 completely inhibited luteal cell apoptosis, and revealed the persistence of the corpora lutea in CB154-treated rats (Wutke and Meites, 1971). In the present study, the increase in the number of corpora lutea was attributed to the reduction of apoptosis in corpora lutea via suppression 

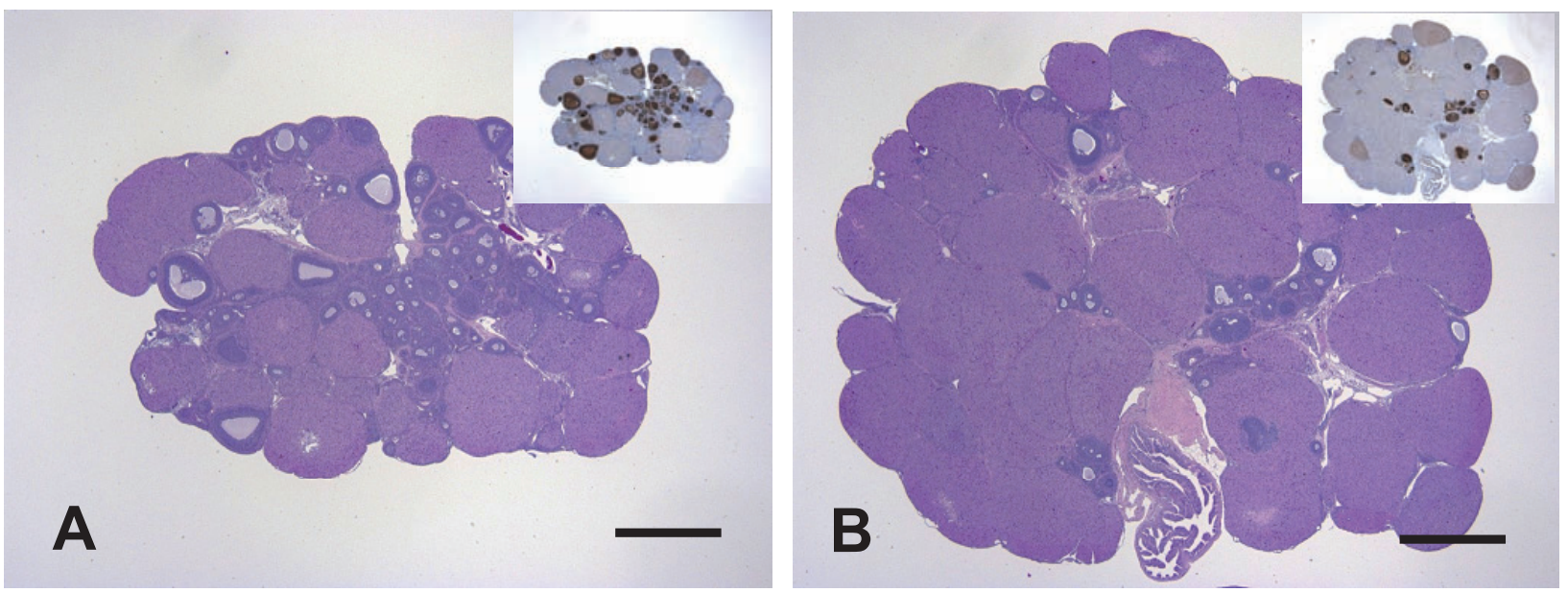

Fig. 2. Histopathological examination of ovaries from rats treated with 0 (A) or $2.0 \mathrm{mg} / \mathrm{kg}$ (B) of bromocriptine in 4-week repeated-dose toxicity study. Scale bars: $1 \mathrm{~mm}$.

A: Control group. Ovarian follicles and corpora lutea are normal. Hematoxylin-eosin staining. Inset shows serial section of A, immunostained with PCNA. Counterstained with hematoxylin.

B: Bromocriptine $2.0 \mathrm{mg} / \mathrm{kg}$ group. Including many corpora lutea. Hematoxylin-eosin staining. Inset shows serial section of B, immunostained with PCNA. Counterstained with hematoxylin.

of prolactin secretion by bromocriptine treatment. No disturbance of estous cyclicity suggests that increased previously formed corpora lutea by the treatment don't have progesterone production activity.

In other organs, the pituitary showed a histopathological change in atrophy of intermediate lobe cells. Bromocriptine reportedly decreased the capacity of the intermediate lobe of the pituitary to synthesize proopiomelanocortin and $\alpha$-melanocyte stimulating hormone via stimulation of the D-2 dopamine receptor and thereby cause atrophy of the intermediate lobe cells of pituitary (Beaulieu et al., 1984). Therefore, it seems that atrophy of intermediate lobe cells in the present study exhibited a similar mechanism.

In the female fertility study, there were no deaths or dose-related abnormalities in clinical signs in females at any dose level. No effects of bromocriptine administration were observed on the estrous cycle and copulation. However, no animals in the 0.4 and $2 \mathrm{mg} / \mathrm{kg}$ groups were pregnant. At necropsy of dams, no effects of bromocriptine administration were observed on the number of corpora lutea, implantations, and pre- and post-implantation loss index in the $0.08 \mathrm{mg} / \mathrm{kg}$ group, which was confirmed to copulation. Bromocriptine, the dopamine receptor agonist, dramatically reduces the plasma prolactin concentration and induces hypoprolactinemia (Dissaneevate and Warne, 1998). Hypoprolactinemia caused by bromocriptine was reported to alter corpus luteum formation and ovary function in female rats (Kauppila et al., 1988). Bromocriptine-induced blockade of prolactin surges and subsequent reduction in progesterone secretion during very early pregnancy in the rat serve to prevent implantation (Kofler et al., 1981; Müller et al., 1980). Inhibition of implantation observed in rats was expected on the basis of bromocriptine's ability to inhibit prolactin secretion, since the maintenance of functional corpora lutea and hence implantation is a prolactin-dependent phenomenon (Richardson et al., 1984). From these findings, the inhibition of implantation in the present study was considered due to administration of bromocriptine. Based on these results, NOAEL was estimated to be the highest dose level, $2 \mathrm{mg} / \mathrm{kg}$, for general toxicological effects on female animals, $0.08 \mathrm{mg} / \mathrm{kg}$ for reproductive function of female animals and early embryonic development.

In conclusion, it is proposed that a 2 -week administration period is sufficient to detect the ovarian toxicity of bromocriptine in the repeated-dose toxicity study. The ovarian pathological findings in the repeated-dose toxicity study performed with sufficiently enough dose levels would predict alterations in female reproductive function in the female fertility study. Furthermore, the NOAELs focused on the ovary for the repreated-dose toxicity studies, and that for the female fertility study were at the similar dosage level in the present study. 
Table 7. Clinical observations and findings on caesarean section in female fertility study

\begin{tabular}{|c|c|c|c|c|}
\hline Dose (mg/kg/day) & 0 (Control) & 0.08 & 0.4 & 2 \\
\hline No. of Animals (Female) & 10 & 10 & 10 & 10 \\
\hline Clinical Observations & - & - & - & - \\
\hline \multicolumn{5}{|l|}{ Body Weight (g) } \\
\hline Day 14 of treatment ( premating ) & $270.1 \pm 13.7$ & $270.7 \pm 17.8$ & $265.9 \pm 13.9$ & $268.0 \pm 13.8$ \\
\hline Day 14 of pregnancy (necropsy day) & $342.6 \pm 18.7$ & $350.9 \pm 15.7$ & $-2)$ & $-2)$ \\
\hline \multicolumn{5}{|l|}{ Food Consumption (g/day/animal) } \\
\hline Day 14 of treatment (premating) & $18.5 \pm 2.3$ & $18.6 \pm 2.9$ & $18.4 \pm 2.3$ & $18.8 \pm 2.0$ \\
\hline Day 7 of Pregnancy & $22.8 \pm 1.9$ & $23.9 \pm 1.1$ & $-2)$ & $-2)$ \\
\hline Estrous Cycle (day) before mating & $4.2 \pm 0.3$ & $3.9 \pm 0.2$ & $4.0 \pm 0.0$ & $4.0 \pm 0.0$ \\
\hline No. Animals with Irregular Estrous Cycle ${ }^{1)}$ & $0 / 10$ & $0 / 10$ & $0 / 10$ & $0 / 10$ \\
\hline No. Animals Mated & 10 & 10 & 10 & 10 \\
\hline No. Animals Copulated & 10 & 10 & 10 & 10 \\
\hline No. Pregnant Animals & 10 & 10 & 0 & 0 \\
\hline Necropsy Findings & - & - & - & - \\
\hline No. Corpora Lutea & $15.3 \pm 1.3$ & $15.4 \pm 1.6$ & $-2)$ & $-2)$ \\
\hline No. Implantations & $14.6 \pm 1.1$ & $14.8 \pm 1.2$ & $-2)$ & $-2)$ \\
\hline Pre-implantation Loss $(\%)^{3)}$ & $4.4 \pm 1.3$ & $3.4 \pm 7.1$ & $-2)$ & $-2)$ \\
\hline No. Live Embryo & $14.0 \pm 1.5$ & $12.8 \pm 2.3$ & - 2) & $-2)$ \\
\hline No. Dead Embryo & $0.6 \pm 0.8$ & $2.0 \pm 2.2$ & - 2) & $-2)$ \\
\hline Post-implantation Loss $(\%)^{4)}$ & $4.2 \pm 5.9$ & $13.5 \pm 15.2$ & - 2) & $-2)$ \\
\hline
\end{tabular}

Values represent mean \pm S.D.

- : No noteworthy findings

1) Estrous cycle was evaluated as irregular cycle considering frequency of irregular cycle (consecutive estrous or prolongation of estrous cycle) in control animals.

2) Not examined because there were no pregnant females.

3) (No. of corpora lutea - No. of implantations) / No. of corpora lutea x 100.

4) (No. of implantations - No. of live fetuses) / No. of implantations $x 100$.

\section{REFERENCES}

Beaulieu, M., Goldman, M.E., Miyazaki, K., Frey, E.A., Eskay, R.L., Kebabian, J.W. and Cote, T.E. (1984): Bromocriptine-induced changes in the biochemistry, physiology, and histology of the intermediate lobe of the rat pituitary gland. Endocrinology, 114, 1871-1884.

Dissaneevate, P. and Warne, G.L. (1998): Hyperprolactinaemia and pituitary adenomas in adolescence. J. Pediatr. Endocrinol. Metab., 11, 531-541.

Flückiger, E. and Wagner, H.R. (1968): 2-Br- $\alpha$-Ergokryptin: Beeinflussung von Fertilitat and Laktation bei der Ratte. Experientia, 24, 1130-1131.

Flülckiger, E., Del Pozo, E. and Von Werder, K. (1982): Prolactin. In Physiology, pharmacology and clinical findings., pp.32-37, Springer-Verlag, Berlin.

Gaytán, F., Bellido, C., Morales, C. and Sánchez-Criado, J.E. (1998): Both prolactin and progesterone in proestrus are necessary for the induction of apoptosis in the regressing corpus luteum of the rat. Biol. Reprod., 59, 1200-1206.

Kauppila, A., Martikainen, H., Puistola, U., Reinilä, M. and
Rönnberg, L. (1988): Hypoprolactinemia and ovarian function. Fertil. Steril., 49, 437-441.

Kiya, T., Endo, T., Goto, T., Yamamoto, H., Ito, E., Kudo, R. and Behrman, H.R. (1998): Apoptosis and PCNA expression induced by prolactin in structural involution of the rat corpus luteum. J. Endocrinol. Invest., 21, 276-283.

Kofler, R., Tabarelli, M., Berger, P. and Wick, G. (1981): In vivo studies on prolactin function in the female rat: Divergent effects of treatment with bromoergocryptine and antisera to rat prolactin. J. Reprod. Immunol., 3, 219-225.

Müller, U., Bauknecht, Th. and Siebers, J.W. (1980): The effect of bromocriptine during early pregnancy in the rat: Inhibition of implantation. Acta Endocrinol., 94, 268-272.

Richardson, B.P., Turkalj, I. and Fuckiger, E. (1984): Bromocriptine. In Safety Testing of New Drugs. Laboratory Predictions and Clinical Performance. Chap. 3, Laurence, D.R., McLean, A.E.M., Weatherall, M. (eds.), pp.19-63, Academic Press, London.

Rothchild, I. (1981): The regulation of the mammalian corpus luteum. Recent Prog. Horm. Res., 37, 183-298.

Rothchild, I. (1996): The corpus luteum revisited: Are the paradox- 
Ovarian toxicity study of bromocriptine in female rats

ical effects of RU486 a clue to how progesterone stimulates its own secretion? Biol. Reprod., 55, 1-4.

Wutke, W. and Meites, J. (1971): Luteolytic role of prolactin during the estrous cycle of the rat. Proc. Soc. Exp. Biol. Med., 137,
988-991.

Yamada, T., Ohsawa, K. and Ohno, H. (1988): The usefulness of alkaline solutions for clearing the uterus and staining implantation sites in rats. Jikken Doubutsu, 37, 325-331. 